\title{
FACTORS AFFECTING THE EXPECTATION OF CASUALTIES IN THE VIRTUAL RANGE TOXICITY MODEL
}

\author{
José Sepúlveda \\ Luis Rabelo \\ Jaebok Park \\ Fred Gruber \\ Oscar Martínez \\ Department of Industrial Engineering and Management Systems \\ University of Central Florida \\ Orlando, FL 32816-2993, U.S.A.
}

\begin{abstract}
The Virtual Range (VR) is an environment that integrates in a seamless fashion several models to improve complex systems visualization. A complex system is a non-linear system of systems whose interactions bring together interesting emergent properties that are very difficult to visualize and/or study by using the traditional approach of decomposition. The VR Toxicity Model as described here represents the different systems that interact in the determination of the expectation of casualties $\left(E_{c}\right)$ resulting from the toxic effects of the gas dispersion that occurs after a disaster affecting a Space Shuttle within 120 seconds of liftoff. We present a detailed description of the VR and the factors affecting $E_{c}$. The system will help local authorities to estimate the population at risk in order to plan for areas to evacuate and/or for the resources required to provide aid and comfort and mitigate damages in case of a disaster.
\end{abstract}

\section{BACKGROUND}

In the face of a disaster (natural, accidental, or man-made, e.g., terrorism), authorities need to determine the population at risk. If toxic gases are released, there is a need to predict where the gas plume will go, how far it will extend, and what the expected concentration of toxins and health consequences will be.

The Virtual Range Toxicity Model's goal is to determine the population at risk and the expectation of casualties $\left(E_{c}\right)$ as a result of toxic gas dispersion when faced with disaster within 120 seconds of an orbiter's liftoff. The system will help local authorities to estimate the population at risk in order to plan for areas to evacuate and/or for the resources required to provide aid and comfort and mitigate damages.

We visualize the range as the volume of space through which the vehicle must pass on its way to and from orbit. We are particularly interested in the projection of that vol- ume over land and the people there that may be exposed in the event of a disaster. The actual dimensions of the volume and its projection over land depend on the vehicle's speed and direction and the risk component being analyzed. For example, the volume (and the corresponding projection over land) for the impact of gas dispersion will be considerably larger (and have a different shape) than the volume and projection resulting from the orbiter's resulting debris. As the vehicle moves, the range encompasses new volumes of space and leaves behind sections that fall out of range of potential hazards. The corresponding projection over land also changes dynamically in size and shape.

Toxic gas-related risk is a factor of exposure duration and toxic propellant concentration or dosage that would result in casualties (death or incapacitating injury) of normal and sensitive people in a given population area.

Table 1 displays the most commonly used Shuttle propellants. Public exposure to values above the ceiling concentration may cause casualties. Values in the last column reflect time weighted average concentrations that may cause casualties.

Table 1: Commonly used Shuttle Propellants

\begin{tabular}{|c|c|c|}
\hline \multirow[b]{2}{*}{ Toxicant } & \multicolumn{2}{|c|}{ Toxic Concentration } \\
\hline & $\begin{array}{l}\text { Ceiling } \\
\text { [ppm] }\end{array}$ & $\begin{array}{l}\text { 60-min } \\
\text { TWA [ppm] }\end{array}$ \\
\hline $\begin{array}{l}\text { Ammonium Perchlorate/ } \\
\text { Aluminum (solid propellant) }\end{array}$ & 10 & 2 \\
\hline Hydrazine & - & 2 \\
\hline Nitric Acid $\left(\mathrm{HNO}_{3}\right)$ & 4 & 2 \\
\hline $\begin{array}{l}\text { Mixed Nitrogen Oxides (NO, } \\
\mathrm{NO}_{2}, \mathrm{~N}_{2} \mathrm{O}_{4} \text { ) }\end{array}$ & 4 & - \\
\hline
\end{tabular}

For the effects of this paper, the VR focuses on the health impact of the release of large amounts of hydrochloric acid $(\mathrm{HCl})$, a major toxicant in the event of a loss of ve- 
hicle. The effect of exposure to $\mathrm{HCl}$ may range from mild irritation and headache to incapacitation due to constriction of the airway and lack of oxygen delivery to the brain. The analysis for other toxicants resulting from a Shuttle disaster will be similar.

\section{THE VR'S ARCHITECTURE}

The VR integrates a Range Safety Simulation model, Geographic Information Systems (GIS), population data, gas dispersion models, and weather information. The architecture is modular and uses commercial off-the-shelf (COTS) applications such as ARENA, CALPUFF, and ArcMap so that it can be easily applied to other shuttle models and/or other launch operation areas.

Figure 1 shows the architecture of the Virtual Range Model. We use Monte Carlo simulation to account for the effect on risk of factors such as vehicle position and consumption of propellants, wind uncertainties, and vehicle guidance and performance deviations. The need for a simulation capability is paramount. For example, toxic gas impact risk is affected by variability in the meteorological and launch vehicle parameters, wind uncertainties, and other weather related characteristics. We also use Monte Carlo simulation to perform sensitivity analyses. For any planned flight path, sensitivity analyses are needed to determine how $\mathrm{E}_{\mathrm{c}}$ varies with changes in input parameters, such as type of vehicle and wind velocity. These sensitivity analyses will identify parameters with the largest impact on the value of $E_{c}$ and, therefore, show where modeling accuracy is most important.

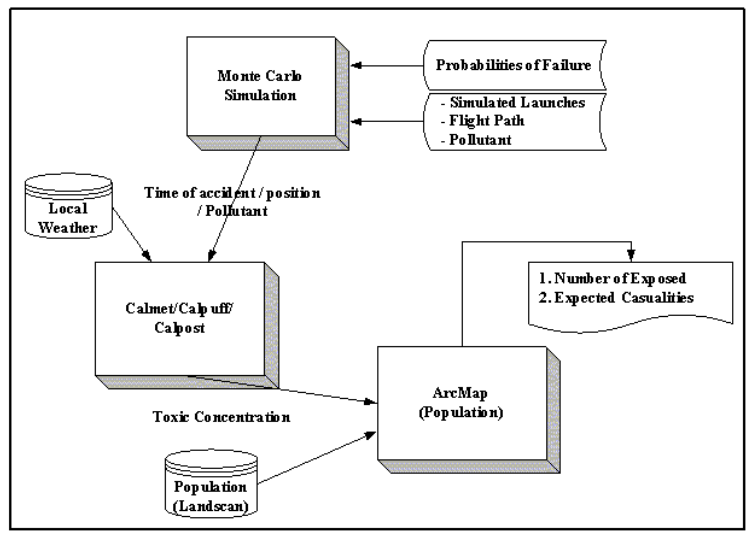

Figure 1: VRTM Architecture

The VR incorporates flight trajectory data and weather information in and around Kennedy Space Center (KSC), a model of the toxics dispersion tailored for the NASA Shuttle at low altitudes, a GIS to visualize the area over land affected by the disaster, a population model to determine the number of people exposed in that area, and a probabilistic calculator/simulator to compute $\mathrm{E}_{\mathrm{c}}$.
If an accident occurs, the model determines the position, volume, and initial dispersion velocity of the released pollutants. These values are the input to CALPUFF - a multi-layer, multi-species, non-steady state Lagrangian puff dispersion model - which in turn predicts the toxic concentrations for the toxicant at a specified time after the onset of the accident. These values determine the envelope over land where the pollutant concentration exceeds the ceilings imposed by the pollutant's Exposure Response Functions (ERFs). We use the number of exposed people under that envelope to estimate the number of casualties for that simulated disaster resulting from exposure to toxic levels of the released toxic propellant.

The scope for $E_{c}$ calculation is restricted to gas dispersion, which we focus on displaying boundaries for. We use as critical values the concentrations defined for an $\mathrm{E}_{\mathrm{c}}=$ $30 \times 10^{-6}$, e.g., an $\mathrm{E}_{\mathrm{c}}$ of thirty casualties in a million launches, the critical value used by NASA when making a GO-NOGO launch decision. An easy-to-use, "intuitive" interface provides numerical and graphical summaries of potential outcomes, with user-defined preferences for the display of units of measure, geographic locations, and time values.

\section{FACTORS AFFECTING $\mathrm{E}_{\mathrm{C}}$}

This section describes the different model components and static and dynamic data integrated in the VR. The section focuses on the factors that may significantly affect the computation of the expectation of casualties resulting from the toxic effects of the gas dispersion that occurs after a disaster affecting a Space Shuttle within 120 seconds of liftoff.

\subsection{Flight Path}

Figure 2 displays the typical launch sectors for launches from the Eastern Range (Cape Canaveral Air Force Station and Kennedy Space Center) (AST 2002).

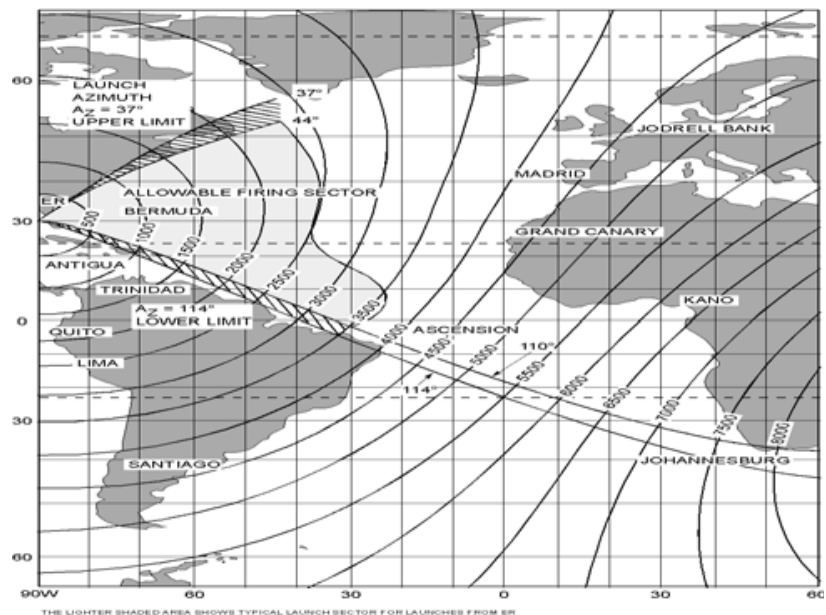

Figure 2: The Eastern Range 
In general, vehicles are launched in an easterly direction and on an azimuth that provides protection for land masses and populated areas on and off the facility, including the Caribbean Islands, Bermuda, the northeast coasts of South America, and Africa. For polar launches the azimuth upper limit is $37^{\circ}$ and the lower limit is $44^{\circ}$. For equatorial launches the azimuth upper and lower limits are $110^{\circ}$ and $114^{\circ}$, respectively.

The path of the shuttle for equatorial launches is calculated from data of past launches given in EFG (Earth-fixed geocentric) coordinates. This information was converted into latitude, longitude, and altitude assuming a spherical model of Earth. Because of this assumption the conversion gave us an error of less than $0.5 \%$ as compared to the real position of the Pad39a in Kennedy Space Center. The altitude was obtained using as reference the distance from the center of the Earth to the position of the shuttle before launch. Using this method the calculated altitude at which the Solid Rocket Boosters separation occurs was $44 \mathrm{~km}$. In order to meet the data requirements of CALPUFF, the resulting data was translated into UTM NAD 27 Zone 17. (National Imagery and Mapping Agency 2004).

The first factor that may be significant is the direction (polar, equatorial) of the launch. Figures $3 \mathrm{a}$ and $3 \mathrm{~b}$ present the VR interface. It does not yet offer the option for a launch direction. So far we have simulated equatorial launches only.

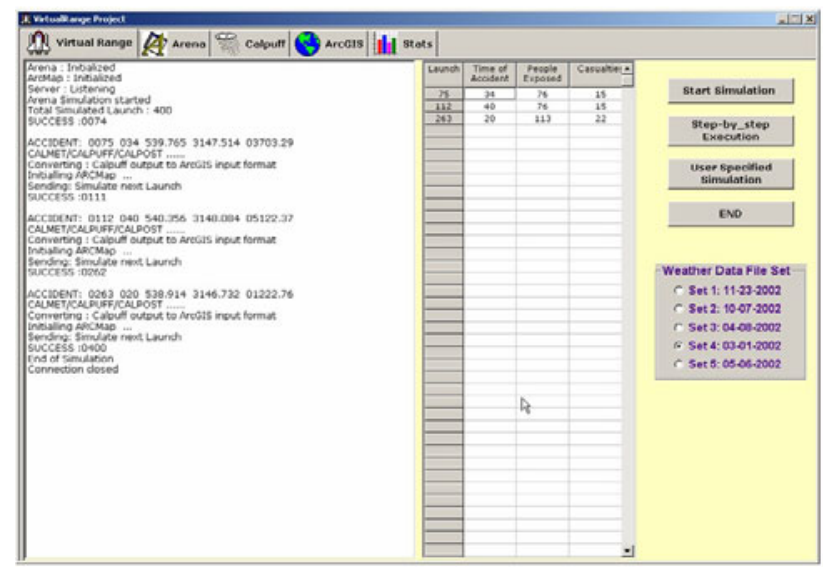

Figure 3a: The Virtual Range Interface

\subsection{Probabilities of Failure for the Shuttle}

The second factor is the exact location where the accident occurs. The VR interface provides the analyst the ability to select a random occurrence for the accident (e.g., to use MonteCarlo Simulation) or to "fix" the time of the accident. There is also a third time-related option, which is to specify a series of observations at fixed time intervals (for example, at 0, 10, 20,30, etc. seconds after launch).

Monte Carlo simulation works by generating random numbers based on probabilities of occurrence of certain events. Figure 4, adapted from a report on potential causes

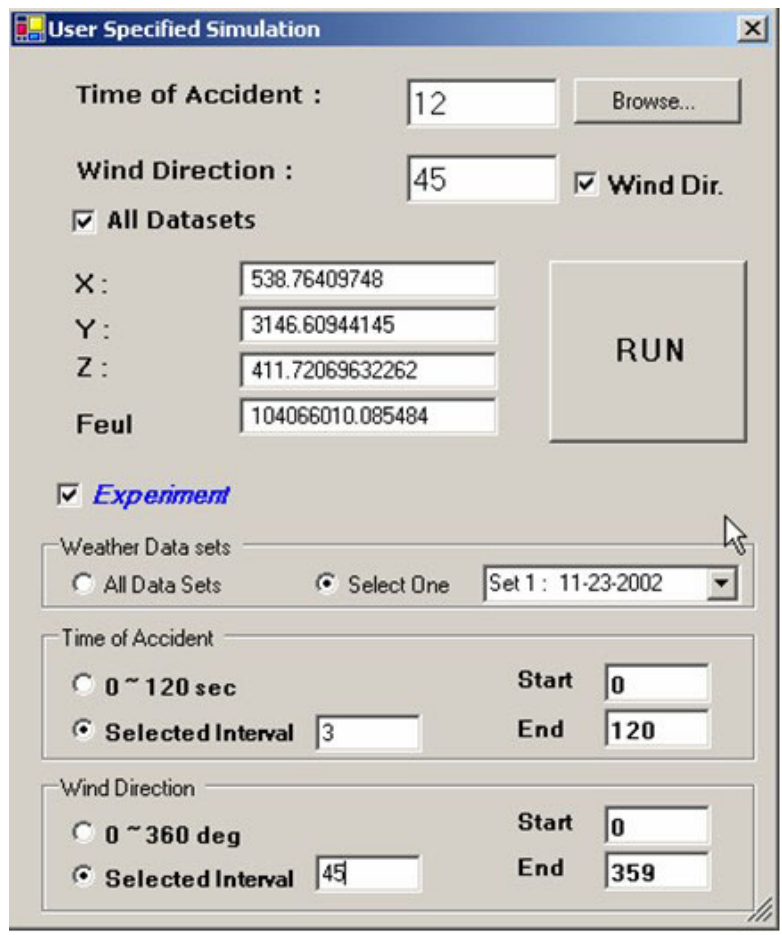

Figure 3b: The Virtual Range Interface

for a loss of vehicle prepared in 1995 by Fraggola and Maggio (Fraggola and Maggio 1995), presents the total probability of losing the vehicle due to the failure of the different systems and subsystems of the shuttle. In order to obtain the probability of losing the vehicle at the different stages, the first 120 seconds were divided into representative events associated to the main components such as external tank, space shuttle main engine, integrated solid rocket booster, and orbiter.

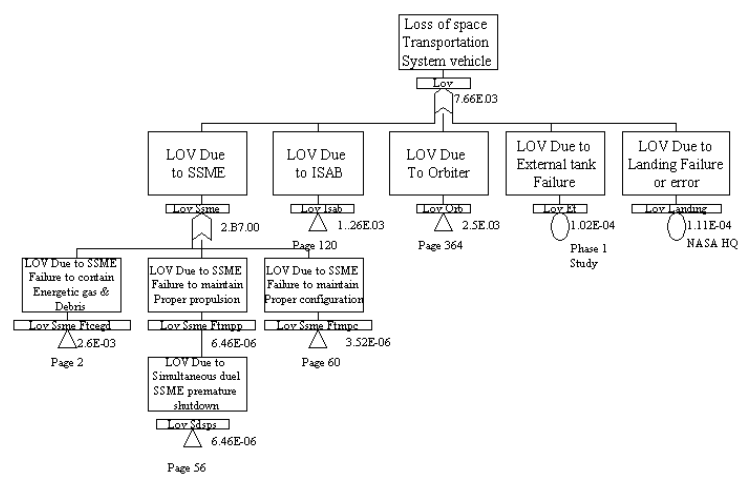

Figure 4: Probabilities of Failure for the Shuttle

\subsection{The Toxicity Model}

\subsubsection{Shuttle Toxicants}

Mixed oxides of nitrogen (including nitrogen tetroxide) are used as oxidants for the hydrazine fuels, which are used in 
relatively small amounts during the Orbiter Maneuvering Stage to guide the orbiter in space. Nitric acid is the major combustion product. In order to launch the shuttle into space, the shuttle relies upon two solid rocket boosters. These contain aluminum powder as fuel and ammonium perchlorate as its oxidizer. Hydrochloric acid $(\mathrm{HCl})$ is a major combustion product.

Due to its relative quantity, the expected dispersion of $\mathrm{HCl}$ gas (density 1.26) is the major determinant of shuttle GO-NOGO decisions. The gas is initially exhausted as an aerosol, which dissipates within a few minutes of flight and remains as gas. With normal operation of the shuttle, total exhaust of $\mathrm{HCl}$ is 163.3 tons during the first 15 kilometers of flight. About 72.5 more tons are exhausted by two minutes after launch (AIAA 1991). In the event of a disaster, the Solid Rocket Boosters (SRBs) separate from the shuttle, burning like "roman candles" as they fall.

\subsubsection{The Gas Dispersion Model}

The health impact of the release of large amounts of hydrochloric acid, a major toxicant in the event of a loss of vehicle, may be catastrophic. The effect of exposure to $\mathrm{HCl}$ may range from mild irritation and headache to incapacitation due to constriction of the airway and lack of oxygen delivery to the brain.

If a "loss of vehicle" event occurs close enough to liftoff, it is possible under some meteorological conditions that the ground concentration would exceed $7 \mathrm{ppm}$, the limit short-term exposure limit (STEL) for $\mathrm{HCl}$ for normal people (Hill Brothers Chemical Co. 2001). For $\mathrm{HCl}$, mild symptoms include irritation and headache, which are reversible within 48 hours and do not interfere with normal activity or require medical attention (Philipson 1999). Moderate symptoms include cough and shortness of breath, and medical attention might be sought. Severe symptoms include disorientation due to constriction of the airway and consequent shortfall in delivery of oxygen to the brain; changes to lung tissue are irreversible in this category. Of course, the STEL values for sensitive people (children, the elderly, and people with asthma or other respiratory disease) are even smaller.

For the evaluation of the gas dispersion and toxic effect we use CALPUFF, developed and distributed by Earth Tech, Inc (Earth Tech 2004). CALPUFF simulates the effects of time and space varying meteorological conditions on pollutant transport, transformation, and removal under inhomogeneous and non-stationary conditions with a onehour time step. CALPUFF has modules to assess toxic effects of specific chemical agents and factors such as variability of meteorological conditions, dry deposition and dispersion over a variety of spatially varying land surfaces, low wind speed dispersion, or pollutant wet removal.

There are several factors associated with CALPUFF that may affect the value of $E_{c}$. The ones we focus on are the initial speed of the toxic plume, the weather conditions (humidity, temperature, etc.), and the wind direction.

\subsubsection{The Weather Factor}

CALMET, CALPUFF's pre-processor of weather related information requires four types of input files: surface meteorological data, upper air data, overwater observations and geophysical data. (Earth Tech 1997, 2002) The weather information that we gathered corresponds to days in 2002 in which a launch took place, specifically March 1, April 8, June 5, October 7, and November 23. In simulating future launches, for a given launch window (projected day and time for launch), we will gather similar weather information that occurred for the same time frame within the same week in the previous three years and use the average and extreme values observed for the simulation.

The surface meteorological observations were obtained from the National Oceanic and Atmospheric Administration (NOAA) website (National Oceanic and Atmospheric Administration 2004). CALMET's meteorological data files require hourly observations of wind speed, wind direction, temperature (part of surface data file), cloud cover, ceiling height, surface pressure, relative humidity, and precipitation type code. We used the data from four different stations in Florida: Orlando (2), Daytona Beach, and Melbourne. None of these stations had the surface pressure, cloud cover, or precipitation type code, so it was necessary to use CALMET's default values.

The upper air observations were also obtained from the NOAA website. This set of observations contains twicedaily observed vertical profiles of wind speed, wind direction, temperature, pressure, and elevation. The data was obtained from station XMR in Cape Canaveral, Florida.

For overwater data, CALMET requires the overwater transport and dispersion. For this purpose it is necessary to have the following information: Air-sea temperature difference, air temperature, relative humidity, overwater mixing high, and wind speed and direction. The information collected was taken from the closest buoy, in this case Station 41009 - CANAVERAL 20 NM East of Cape Canaveral. This information has been obtained from the National Data Buoy Center a division of the NOAA (National Data Buoy Center 2004).

Some of the data that was found in the NOAA site did not match the requirements of CALMET, so we calculated the missing parameters with theoretical formulas. For instance, the relative humidity was not part of the information found in the NOAA's files. Therefore, we used the vapor pressure, the saturation vapor pressure, the dew point temperature, and ambient temperature found from the NOAA to calculate it.

Geophysical data inputs required by the CALMET model include gridded fields of terrain elevations and land use categories. Optional fields include surface roughness length, albedo, Bowen ratio, soil heat flux constant, anthropogenic heat flux, and vegetative leaf area index.

Some the characteristics of the obtained weatherrelated data are presented in Table 2. Note that the wind 
speed used by CALPUFF will depend on where the accident occurs. If at low altitude, the first two rows in Table 2 will be used; otherwise the last two rows will determine the "default" values used.

Table 2: Weather During Launch Days

\begin{tabular}{|l|c|c|c|c|}
\hline & Min & Max & Average & St. Dev \\
\hline $\begin{array}{l}\text { Surface data } \\
\text { wind speed }\end{array}$ & 1.67 & 6.43 & 4.46 & 2.18 \\
\hline $\begin{array}{l}\text { Surface data } \\
\text { wind angle }\end{array}$ & 30 & 122.5 & 80 & 41.00 \\
\hline $\begin{array}{l}\text { Upper Air data } \\
\text { wind speed }\end{array}$ & 113.33 & 305 & 189.13 & 80.28 \\
\hline $\begin{array}{l}\text { Upper Air data } \\
\text { wind angle }\end{array}$ & 3.63 & 13.85 & 8.07 & 3.94 \\
\hline
\end{tabular}

In the VR interface, the analyst is given the option of selecting any of the given dates. The analyst can also change the default values for the wind speed and angle in any selected day. As an alternative, the "All days" option may be selected which results in one independent simulation run for each of the selected weather profiles.

\subsection{Geographic and Population Models}

The VR uses ArcGIS - a powerful commercial GIS application that provides data visualization, query, analysis, and integration capabilities along with the ability to create and edit geographic data - to identify the region covered by the dispersed gas.

The area covered in our simulation is basically the area near and around the Cape Canaveral region, which includes mainly Brevard and Orange Counties and a large part of the sea around the Cape. The simulation covers about $150 \mathrm{~km}$ in each direction from the source (Cape Canaveral). Since this area is a flat, noncomplex terrain and surrounded by sea, it has a good flow of winds, pressure and temperature variations through it. So, the weather data plugged into the model plays an important role in the simulation. The area covered by the simulation is divided into a number of grids with equal spacing to facilitate the study of concentrations of the explosions in the area considered. Each grid can be a square block, whose side can range from 10 s of meters to 100 s of kilometers.

\subsubsection{Population Model}

Using the LandScan Global Population Database - a public domain database of the world's population developed by Oak Ridge National Laboratory (ORNL) - to present population data associated with the covered region, the VR determines the population at risk for that specific riskcomponent (LandScan 2004).

LandScan includes the best available census counts (usually at province level) for each country and allocates these figures into rural and urban population distributions on a 30" X 30" lat/long grid cell system. To assign values to a specific grid cell, LandScan calculates a probability coefficient for each cell and applies the coefficients to the census counts. The probability coefficient is based on slope, proximity to roads, land cover, nighttime lights, and an urban density factor.

\subsubsection{Exposure Response Functions}

Figure 5 shows Exposure Response Functions (ERFs) for $\mathrm{HCl}$ for sensitive and normal people subject to a 10-minute exposure. The sensitive population was defined as children through age 14 and adults aged 75 and over, as well as all others with respiratory illnesses. In Brevard County, recent census data shows that $42 \%$ of the population is made up of those 18 and younger and those 65 and older and this number is expected to increase to over $55 \%$ by the year 2010 (United Way of Brevard County 2002).

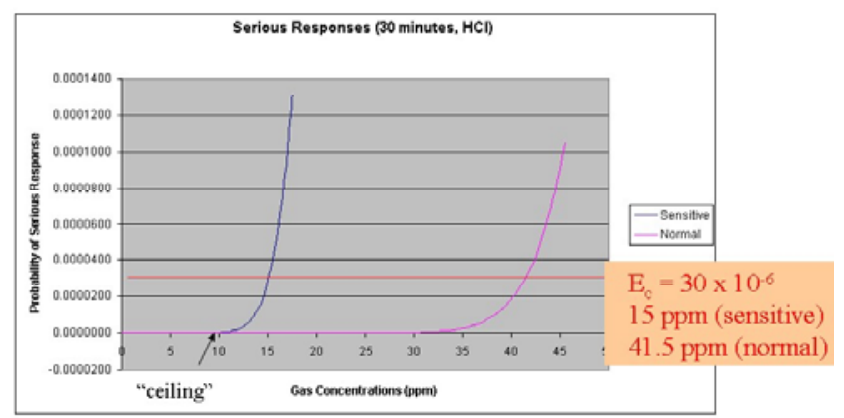

Figure 5: Exposure Response Function for $\mathrm{HCl}$

These curves show that concentrations of $15 \mathrm{ppm}$ and $41.5 \mathrm{ppm}$ of $\mathrm{HCl}$ result in an expectation of casualties of about 30 in a million $\left(\mathrm{E}_{\mathrm{c}}=30 \times 10^{-6}\right)$ for sensitive and normal people, respectively.

ERF curves have been computed for nitric acid aerosol, nitrogen dioxide, and hydrochloric acid. They were constructed by a panel of about 20 expert toxicologists who provided best estimates of the 1- and 99-percentiles of expected casualties. Below the first percentile, "essentially no one in a population of a given sensitivity category would be affected to a given level of severity." Above the $99^{\text {th }}$ percentile, "essentially all in the population would be so affected." Twelve estimates (with ranges of uncertainty) for each substance and duration of exposure $(10,30,60$, and $120 \mathrm{~min}$ utes) were provided by members of the panel of experts: one for each percentile, casualty type (mild, moderate, and severe), and victim type (sensitive, normal). Some of the panelists computed duration estimates from 1-hour estimates according to Haber's Law, which states that "an effect level is directly proportional to exposure concentration multiplied by time" (Philipson 1999). Once these estimates were decided upon by the panel, ERF curves were then calculated as cumulative distributions. 


\subsubsection{Geographic Data Model}

ArcGIS is used along with LandScan Global Population Database. In this GIS environment, the model of population distribution is integrated with the gas dispersion model to calculate $\mathrm{E}_{\mathrm{c}}$ for that risk component given a loss of vehicle.

Spatial Analyst, an extension toolset in ArcGIS, is used to generate the query on the $\mathrm{HCl}$ data from the Gas Dispersion Model to select the region where the concentration of the $\mathrm{HCl}$ exceeds a critical value. Zonal Statistics calculates the statistics for each zone of a zone dataset based on values from another dataset. A zone is a region in which all the cells in a raster have the same value, regardless of whether or not they are contiguous. The sum of the output gives the total number of people affected in that critical $\mathrm{HCl}$ concentration zone.

For the VR, the sensitive and normal $\mathrm{HCl}$ severe ERFs were combined according to the sensitive and normal population mix in Brevard County, Florida. A critical value of $15 \mathrm{ppm}$ was used as a baseline. This value represents a value where most sensitive people will be affected but most normal people will not. In the sensitivity analysis we will vary this factor by increasing the critical $\mathrm{HCl}$ concentration by increments of 10 until we reach $45 \mathrm{ppm}$, a value where almost the whole population will be affected.

Figure 6 shows an example of the ArcMap display of a layer of contaminants over Florida.

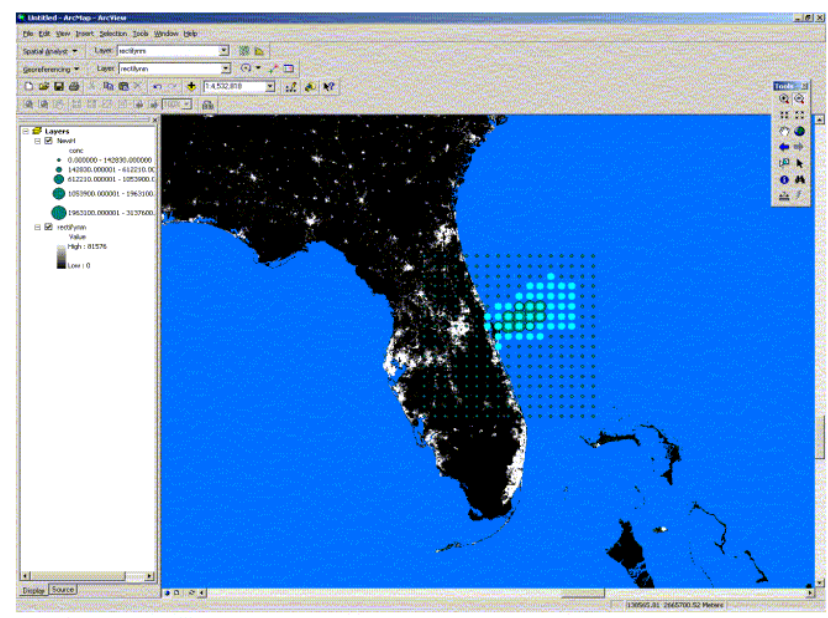

Figure 6: CALPUFF Output Displayed on ArcGIS

Note that Spatial Analyst and LandScan combine to give an estimate of the number of people that may be exposed in the affected area. However, this figure represents an upper limit for the number of people at risk as some, hopefully most, people will be able to take cover or flee the region before the gas dispersion reaches it. Still a sensitivity analysis could be done on the proportion of the exposed people that will actually result incapacitated or dead as a result of the accident.

\subsection{Summary and Conclusion}

\subsubsection{The Virtual Range Model}

In summary, the VR works as follows: An Arena model simulates the time of accident, which is determined by the cumulative probability of accident in ten different stages during a launch. Each of these stages has a different duration and probability of an accident. Once the stage is determined, the time of accident is fixed by equal chance within the stage. Based upon the time of accident, the model references coordinates of path of orbiter and determines the volume of remaining pollutants from the existing model data file.

These values are the input to CALPUFF, which in turn predicts the toxic concentrations for each toxicant after one hour. We enter these values as a layer into ArcMap, to determine the envelope over land where the pollutant concentration exceeds the ceilings imposed by the corresponding ERF. ArcMap's Spatial Analyst has the ability to determine the number of people covered by the displayed layer. We use the number of exposed people and the parameters resulting from the pollutant's ERF (we use as critical values the concentrations defined for $\mathrm{E}_{\mathrm{c}}=30 \times 10^{-6}$ ) to estimate the number of casualties for that simulated disaster resulting from exposure to toxic levels of the released toxic propellant. Repeating the procedure for enough simulation runs, we can get enough information to generate an "average" boundary and its associated confidence interval.

\subsubsection{Initial Results}

In our initial results, the sensitivity analysis shows that wind direction and the time of accident (seconds after launch) have the most significant impact on the number of people on the ground exposed to dangerous concentrations of the toxicant one hour after the onset of the disaster. However, in these runs we varied wind direction from $0 \mathrm{o}$ to $360 \mathrm{o}$ in increments of $45 \mathrm{o}$. In the final runs the limits for variation in wind direction will be given by the extreme values observed in actual launch dates. We expect to get a more detailed picture of the significance of the factors at work (and their interaction) when we apply data mining techniques such as neural networks, support vector machines, cluster analysis, or decision trees.

\subsubsection{Factors to Consider}

The factors selected for the final analysis are summarized in Table 3. The dependent variable in the analysis is the expected number of people on the ground exposed to dangerous concentrations of the toxicant one hour after the onset of the disaster. 
Table 3: Factors Affecting $E_{c}$

\begin{tabular}{|c|c|c|}
\hline Factor & Example & Range \\
\hline $\begin{array}{l}\text { Flight path's azimuth } \\
\text { (direction of the launch) }\end{array}$ & $112^{\circ}$ & $\begin{array}{l}\text { Polar: } 37^{\circ}-44^{\circ} \text {; } \\
\text { ecuatorial: } \\
110^{\circ}-114^{\circ}\end{array}$ \\
\hline $\begin{array}{l}\text { Time of accident [sec- } \\
\text { onds after launch] (sets } \\
\text { altitude and amount of } \\
\text { pollutants released) }\end{array}$ & 15 & $\begin{array}{l}0-120 ; \text { will try } \\
0,5,10,15, \\
20,25, \text { and } 30 \\
\text { seconds. }\end{array}$ \\
\hline $\begin{array}{l}\text { Nature and amount of } \\
\text { the released toxicant } \\
\text { (depends on initial } \\
\text { value, flight time, and } \\
\text { consumption rate) }\end{array}$ & $\mathrm{HCl}, 8$ tons & See Table 2. \\
\hline $\begin{array}{l}\text { Initial velocity of the } \\
\text { gas plume }\end{array}$ & $\begin{array}{c}380 \\
\text { (CALPUFF's } \\
\text { default) }\end{array}$ & $\begin{array}{l}\text { Needs further } \\
\text { research }\end{array}$ \\
\hline Weather conditions & $4 / 8 / 2002$ & $\begin{array}{l}\text { As represented } \\
\text { by } 5 \text { actual } \\
\text { launch dates }\end{array}$ \\
\hline Wind angle (f(altitude)) & 200 & $\begin{array}{l}\text { Limits repre- } \\
\text { sented by an- } \\
\text { gles observed } \\
\text { in actual } \\
\text { launch dates }\end{array}$ \\
\hline $\begin{array}{l}\text { Wind velocity } \\
\text { (f(altitude)) }\end{array}$ & 10 & $\begin{array}{l}\text { Limits repre- } \\
\text { sented by } \\
\text { speeds ob- } \\
\text { served in ac- } \\
\text { tual launch } \\
\end{array}$ \\
\hline $\begin{array}{l}\text { Critical concentration } \\
\text { for the pollutant }\end{array}$ & 15 & $\begin{array}{l}15-45 \text { (from } \\
\text { ERF for } \mathrm{HCl}) \\
\end{array}$ \\
\hline $\begin{array}{l}\text { The proportion of ex- } \\
\text { posed population inca- } \\
\text { pacitated or dead as a } \\
\text { result of the accident }\end{array}$ & $60 \%$ & 0 to $100 \%$ \\
\hline
\end{tabular}

\subsubsection{Conclusion}

In conclusion, the VR develops a prototype of a virtual engineering environment, called the "Virtual Range," that focuses on the first two minutes after lift-off from Kennedy Space Center. The scope for Ec calculation is restricted to toxic gas dispersion, and we focus on displaying boundaries for $E_{c}=30 \times 10^{-6}$. Toxic gas-related risk is a factor of exposure duration and toxic propellant concentration or dosage that would result in casualties (death or incapacitating injury) of normal and sensitive people in a given population area. The VR's easy-to-use, "intuitive" interface provides numerical and graphical summaries of potential outcomes, with user-defined preferences for the display of units of measure, geographic locations, and time values. This paper presented the factors we have selected for an indepth sensitivity analysis of the population at risk, including vehicle trajectory, accident location, vehicle position and consumption of propellants, weather and wind uncertainties, and amount and type of toxicants released. Such factors may significantly affect the computation of the population exposed and the corresponding expectation of casualties resulting from the toxic effects of the gas dispersion that occurs after a disaster affecting a Space Shuttle within 120 seconds of liftoff.

\subsubsection{Future Work}

The modular architecture of the VRTM allows the analysis of new vehicles (e.g., the Crew Exploration Vehicle $(\mathrm{CEV})$ ) and the study of other launching sites. The current environment uses extensively VBA, however, future architectures are contemplating the integration with discreteevent simulation of KSC operations and the utilization of a modified High-Level Architecture (HLA). We will report about these developments in future papers.

\section{ACKNOWLEDGMENTS}

We wish to thank Mr. Jeppie Compton from All Points Logistics, and Dr. James Simpson and Mr. Cary Peaden from NASA Kennedy Space Center for sharing their experience and knowledge with us as we worked. We are also grateful for all the good work provided by the graduate assistants in our Center for NASA Simulation Research Group not listed as co-authors: Ann Dalrymple, Mario Marin, Asisa Musa, Usha Neupane, Amith Paruchuri, Anu Pullati, David Sepúlveda, and Amit Wasadikar.

\section{REFERENCES}

AIAA, Atmospheric Effects of Chemical Rocket Propulsion, 1991.

AST, Operating in the Federal Ranges, Student Training Guide, Safety Inspector Training and Qualification Program, October 2002.

Earth Tech. CALPUFF Modeling System. 2004. Available online via <http: / / earthtec.vwh. net / download/download.htm> (accessed August 19, 2004).

Earth Tech. User Manuals for CALPUFF Version 5, 1997.

Earth Tech. Addendum for CALPUFF Version 6, 2002.

Fragola, J., and G. Maggio, Probabilistic Risk Assessment of the Space Shuttle. Phase 3: A Study of Potential of Losing the Vehicle During Nominal Operation, Vol. 2: Integrated Loss of Vehicle Model. Report submitted by SAIC (Science Applications International Corporation) to NASA, February 1995

Hill Brothers Chemical Company, Material Safety Data Sheet, <http://hillbrothers.com/msds/pdf/ hydrochloric-acid-solution.pdf>, 2001. 
LandScan. Gridded Population of the World. 2004. Available online via <http://sedac.ciesin.org/plue/ gpw/landscan/>(accessed August 19, 2004).

National Imagery and Mapping Agency. The Universal Transverse Mercator Grid. 2001. Available online via <http://mac.usgs.gov/mac/isb/pubs/ factsheets/fs07701.html\#utm> (accessed August 19, 2004).

National Data Buoy Center, a division of the National Oceanic and Atmospheric Administration. Observations Search. 2004. Available online via $<$ http: / / www . ndbc. noaa. gov/> (accessed August 19, 2004).

National Oceanic and Atmospheric Administration. Station 41009 - Canaveral 20 NM East of Cape Canaveral, FL. 2004. Available online via $<$ http: //www.ndbc.noaa.gov/station_page .phtml? station=41009> (accessed August 19, 2004).

Philipson, Lloyd L., An expert elicitation of estimates of exposure limits for space and missile launch toxicants, Technical Report No. 99-400/11.2-01, ACTA, Inc., 1999.

United Way of Brevard County. Tour Sets Stage for Kids \& Seniors Initiative. 2002. Available online via $<$ http: //www. uwbrevard.org/news/newsb ustour.html> (accessed August 19, 2004).

\section{AUTHOR BIOGRAPHIES}

JOSÉ A. SEPÚLVEDA, Ph.D., P.E., is an Associate Professor in the Department of Industrial Engineering and Management Systems at the University of Central Florida in Orlando, Florida. He received an Ingeniero Civil Químico degree from the Universidad Santa María, Valparaíso, Chile, and MSIE, MPH, and Ph.D. (Industrial Engineering) degrees from the University of Pittsburgh. Dr. Sepúlveda is a registered Professional Engineer in Florida and Chile. Dr. Sepúlveda's major areas of research interest are object-oriented simulation, simulation optimization, risk analysis, catastrophe response, measuring and modeling training effectiveness, tasks scheduling in complex and risky environments, and applications of industrial engineering and simulation in health care. He has written two books and numerous publications. His e-mail address is <sepulved@mail.ucf.edu>.

LUIS RABELO, Ph.D., is an Associate Professor in the Department of Industrial Engineering and Management Systems at the University of Central Florida in Orlando, Florida. He received dual degrees in Electrical and Mechanical Engineering from the Technological University of Panama and Master degrees from the Florida Institute of Technology (Computer Engineering, 1987) and the University of Missouri-Rolla (Engineering Management, 1988). He received a Ph.D. in Engineering Management from the University of Missouri-Rolla in 1990 where he also did Post-Doctoral work in Nuclear Engineering and Artificial Intelligence in 1990-1991. He also holds dual MS degrees in Aerospace Systems Engineering \& Management from the Massachusetts Institute of Technology (2001). He has over 125 publications and three international patents. His experience includes Ohio University, BF Goodrich Aerospace, Honeywell Laboratories, the National Institute of Standards and Technology (NIST), NASA, and the Massachusetts Institute of Technology. Dr. Rabelo has expertise in simulation modeling, aerospace engineering, software engineering, and complex systems. His e-mail address is <lrabelo@mail.ucf.edu>.

JAEBOK PARK is currently a Ph.D. candidate in the Institute for Simulation \& Training at the University of Central Florida in Orlando, Florida. He received a B.S. in Electrical Engineering from Korea Naval Academy in 1988, and M.S. in Computer Science from the Western Illinois University in 1994. His Research interests include Distributed Simulation, High Level Architecture and Visualization for HLA-based distributed simulations. His e-mail address is $<$ ja969179@pegasus.cc.ucf.edu> .

FRED GRUBER is a Ph.D. student in the Department of Industrial Engineering and Management Systems at the University of Central Florida in Orlando. He received dual degrees in Electrical and Electronics Engineering from the Technological University of Panama. He has worked as a research assistant with the Center for NASA Simulation Research Group since the fall of 2003. He is a student member of the IEEE and a certified Electrical Engineer in Panama. His areas of interest are simulation, artificial intelligence, signal processing, and information theory. His e-mail address is <fgruber@mail.ucf .edu> .

OSCAR MARTINEZ is a Ph.D. student in the Department of Industrial Engineering and Management Systems at the University of Central Florida in Orlando, Florida. He holds a BS degree in Industrial Engineering from the Universidad Javeriana in Bogotá, Colombia. He has worked as a research assistant with the Center for NASA Simulation Research Group since the fall of 2003. His areas of interest are Simulation, Manufacturing, and Productivity. His email address is comartine@mail.ucf.edu>. 